\title{
A semi-automatic methodology to detect fire scars in shrubs and evergreen forests with Landsat MSS time series
}

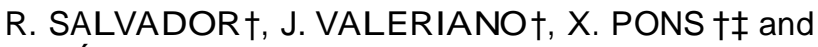 \\ R. DÍAZ-DELGADO†
}

†Centre de Recerca Ecològica i Aplicacions Forestals (CREAF), Edifici C, Universitat Autò noma de Barcelona, 08193 Bellaterra, Spain. ‡Departament de Geografia, Universitat Autò noma de Barcelona, 08193 Bellaterra. Spain; e-mail: x.pons@uab.es

\begin{abstract}
This paper presents a semi-automatic methodology for fire scars mapping from a long time series of remote sensing data. Approximately, a hundred MSS images from diFerent Landsat satellites were employed over an area of $32100 \mathrm{~km}^{2}$ in the north-east of the Iberian Peninsula. The analysed period was from 1975 to 1993. Results are a map series of fire history and frequencies. Omission errors are $23 \%$ for burned areas greater than 200 ha while commission errors are $8 \%$ for areas greater than 50 ha. Subsequent work based on the resultant fire scars will also help in describing fire regime and in monitoring post-fire regeneration dynamics.
\end{abstract}

\section{Introduction}

In Mediterranea n ecosystems fires burn yearly around 0.6 Mha (Vélez 1996). From 1968 to 1994, the number of summer forest fires in coastal eastern Spain have increased at a rate of 21 forest fires per year (Piñol et al. 1998). Despite the variability in total surface burned per year in Spain, there is a spectacular increase when comparing the 50 kha burned yearly in the early 60s with the 450 kha reached in 1995 (Moreno et al. 1998). On the other hand, fire directly influences the structure and spatial distributio $n$ of vegetation (Nieuwenhuis 1987, Callaway and Davis 1993, Davis and Burrows 1994, Johnston and Gutsell 1994, Gracia and Sabaté 1996) but, in turn, vegetation structure may also influence the frequency and size of fires (Minnich 1983).

Satellite images have been used for mapping burned areas, aiding to understand the structure and dynamics of the landscape, particularly at the regional level. Furthermore, mapping fire scars and characterising fire regimes is also of interest to global studies, such as those aimed to quantify carbon exchanges with the atmosphere ( Kasischke et al. 1993, Chuvieco and Martin 1994, Veroustraete et al. 1996, Pereira and Setzer 1996, etc.).

Remote sensing has been applied to characterise fire regimes in forested areas ( Minnich 1983, Richards 1984). Specifically, various methods have been developed to detect changes produced by fire by means of remote sensing techniques. For instance, principal component analysis (PCA) may separate factors of variabilit $y$ in diFerent images (i.e. principal components) (Fung and Le Drew 1987, Chavez and Kwarteng 
1989, Eastman and Fulk 1993, Collins and Woodcock 1996). Thus, factors included in first components are usually related to the general spatial variability and to large phenological changes, while local changes, such as fires, are shown in the subsequent components (Richards 1984, Salvador and Pons 1996). Despite its interest, PCA applicatio $\mathrm{n}$ to fire studies has been restricted to time series comprising few images.

Methodologies based on classification procedures have been also applied to analyze vegetation changes (Hall et al. 1991, Foody et al. 1996). However, as Pereira and Setzler (1993) realised, mapping of burned areas by classification algorithms may lead to very diFerent results depending on the specific parameters used.

Image subtraction is a simple method frequently used in studies of vegetation disturbances. It is based on the subtraction of two images from diFerent dates and on the later selection of burned areas by a threshold value of change. However, choosing the threshold value is not usually easy since the range of output values from the subtraction process is continuous, and pixels that have undergone change are not clearly distinguished from those that have not (Chuvieco 1996). Some examples of this methodology can be found in studies of rainforest deforestation ( Sader 1995, Di Maio and Seltzer 1997) and its use in the location of burned zones has been quite widespread (Kasischke et al. 1993, Kasischke and French 1995, Fernández et al. 1997). A refinement of the subtraction method is based on the calculation of a regression line between pixels of images preceding and following a fire. Pixels within the fire perimeter are usually distinctly separated from the regression line given by invariant pixels (Chuvieco 1996, Fernández et al. 1997).

Finally, change vector analysis (Lambin and Strahler 1994a, 1994b and Lambin 1996) and Fourier transformation s (Ludovic et al. 1994) are other methods applied to detect vegetation changes on image series. Nevertheless, both require a high and regular frequency of images and the latter is more suitable for cyclical changes.

From all sensor bands and indices, NDVI is the most commonly used in studies of detection of burned areas. It takes advantage of the radiometric information of vegetation given by red and near infrared bands, minimising the eFect of diFerent solar angles, relief eFects and allowing comparisons between images of diFerent times of the year (Mather 1987); and moreover, it may be also obtained from almost all earth observation sensors. In addition, there are specific properties that make NDVI suitable for detection of fire scars. For instance, its general response to levels of green biomass irrespective of plant species present (Blackburn and Milton 1995, Gamon et al. 1995) makes it an useful tool to quantify the total vegetation cover (Anderson et al. 1993, Duncan et al. 1993). Although its response becomes saturated when vegetation achieves a 100\% coverage (Danson and Plummer 1995, Steininger 1996) it is specially sensitive in lower coverage.

On the other hand, several drawbacks usually driven by changes in soil properties have been described for the NDVI (Huete 1988, Qi et al. 1993, 1994, Xia 1994, Bannari et al. 1996) and other more complex indices have been proposed. However, the NDVI is still widely used for regional scale studies since detailed soil information required for these new indices is not usually available in such scales or it may be highly variable through time (soil moisture is a clear example).

\section{Objectives}

The main objective of this study is the development of a semiautomatic methodology to discriminate burned sites from a long time series of satellite images covering a relatively large area from a medium/high resolution sensor. 
Specifically, the work aimed to map the scars produced by fires during the 1975-1993 period in the study area and to test these maps using ancillary field information. This study is part of a broader study of fire eFects on the vegetation dynamics in several parts of Europe (EC Lucifer Project).

\section{Material and methods}

\subsection{Study area}

The study region includes the region of Catalonia, with an area of around $32100 \mathrm{~km}^{2}$ and located in the north-east of the Iberian Peninsula, beside the Mediterranean Sea (figure 1). Approximately $60 \%$ of it is covered by vegetation (mainly shrubland and forests) but a dense human settlement has often lead to a considerable fragmentation of vegetation patches. Although there are some highly mountainous areas $(1500-3000 \mathrm{~m})$ with a cold winter climate, the majority of the study area has a Mediterranean climate, with a fair weather and a significant summer drought that frequently leads to forest fires (Terradas and Piñol 1996).

According to the first ecological and forest inventory of Catalonia (Gracia et al. 1997), the current wooded forest surface can be characterised by a $20 \%$ of Pinus sylvestris, a $20 \%$ of Pinus halepensis, a $16.6 \%$ of Quercus ilex, a $12.5 \%$ of Pinus nigra, a $5.5 \%$ of Quercus suber, a $4.8 \%$ of Pinus uncinata, and $4.0 \%$ of Quercus humilis, and a $3.3 \%$ of Pinus pinea; species as Abies alba, Castanea sativa, Fagus

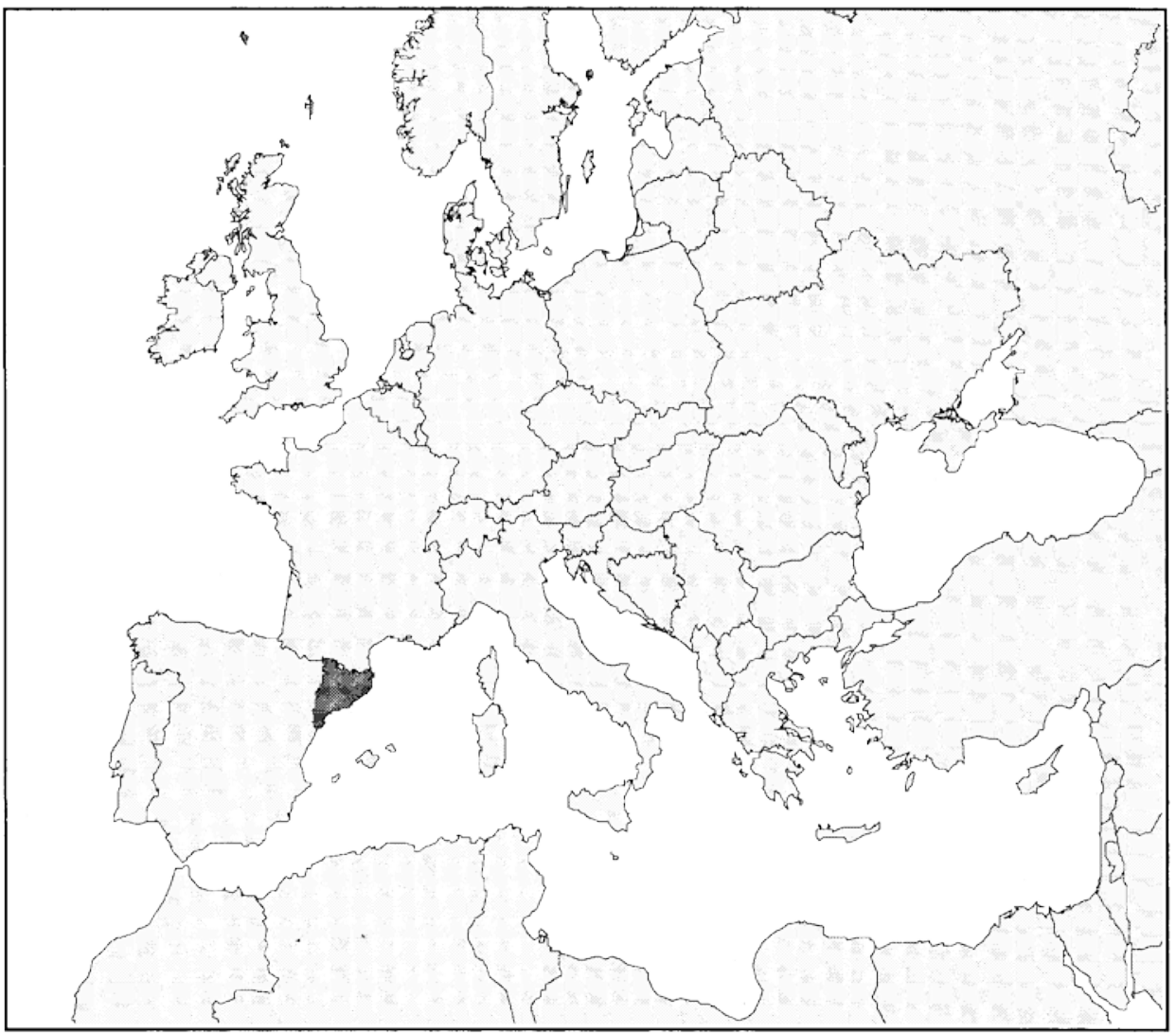

Figure 1. Location of the study area in the European context. 
sylvatica, Pinus pinaster and Quercus cerrioides occupy between $1 \%$ and $3 \%$ of the surface. Evergreen species (31 species) reach the $86 \%$ of the total forested area (from which $73 \%$ of the area is occupied by conifers), while deciduous trees (58 species) cover the $14 \%$.

According to the Corine land cover map, shrublands cover $26.6 \%$ of the total wildland area (1950326 ha), with a diverse specific composition, mainly evergreen (Folch 1987).

The land cover categories considered in this study are the following ones:

1. The totality of the class 3 (forests and semi natural areas), unless the Corine subclasses 3.3.1: Beaches, dunes, sand; 3.3.2: Bare rocks; and 3.3.5: Glacier and permanent snow fields.

2. Within the class 2 (agricultural areas), uniquely the subclass 2.4.3: Land principally occupied by agriculture, with significant areas of natural vegetation.

\subsection{Satellite images}

Fragmentatio $n$ of vegetation and high population restricts the average size of fires. Burned sites in the study area are considerably smaller than those of lessinhabited zones, such as the boreal forest where fires may burn continuously for several weeks. In that case, huge areas become burned and their mapping can be achieved by NOAA-AVHRR images (Kasischke et al. 1993, Kasischke and French 1995). Nevertheless, although the AVHRR sensor has also been used to monitor large fires in the Mediterranean basin (Chuvieco and Martìn 1994, Fernández et al. 1997 ) it is not suitable to carry out detailed mapping of medium fires. On the other hand, although subpixel analysis may be used to quantify the general extent of burned areas (Razafimpanilo et al. 1995), it will fail to give fire boundaries.

Finally, the MSS sensor was selected among sensors with a higher spatial resolution as it provided the longest time series of images. More than a hundred MSS full frames taken on board of Landsat satellites 1, 2, 4 and 5 were acquired from the 1975-1993 period. However, since the study area is quite wide, 2-3 full frames were needed to cover it, resulting in a mean time series of about 40 images.

\subsection{Image corrections}

Images had to be geometrically corrected and properly registered in order to be used in a time series. The correction model of Palà and Pons (1995), based on polynomials and a digital elevation model, was applied to a group of control points over the whole set of images to obtain ortho-images. Although some problems appeared during the geometric correction (particularly in the oldest images where even full rows were sometimes lacking) these were finally solved. Pixels of corrected images had $60 \mathrm{~m}$ width, to preserve at maximum the best MSS spatial resolution.

Standard gain and oFset coeficients for each satellite and period were initially applied (EOSAT 1986) in order to transform digital numbers to radiance levels. Next, the radiometric correction model of Pons and Solé-Sugrañes (1994) was applied to obtain reflectance values, which may allow comparisons between images from diFerent times of the year. However, significant diFerences were even found between contiguous (within the same date and track) reflectance images. Finally, we realised that, in addition to the treatments usually applied to MSS images (Mather 1987), those processed in Europe had been individually stretched taking the specific histogram of each image into account (i.e. varying according to its own proportion of 
clouds and other variable surfaces) (ESA 1979a, 1979b). Eventually we opted to combine the previously used radiometric correction model (but taking into account such stretching) and a final normalisatio $n$ of the diFerent bands by means of invariant training areas (one corrected image of the Landsat $5 \mathrm{MSS}$ was taken as the reference image for the standardisation). Once all images were normalised, NDVI values were calculated from bands 2 and 4 of the MSS sensor -referred to as 5 and 7 for some satellites.

\subsection{Choice of methodology}

Considering the good results of a previous study, in the same area, where fire scars were successfully discriminated from other surfaces by means of a PCA (Salvador and Pons 1996), the same methodology was initially applied to the whole time series. Nevertheless, probably due to the huge amount of images involved, the PCA failed to group all fires in few image components (fires appeared in almost all principal components).

On the other hand, although MSS images were theoretically available every 18 days ( 16 days in Landsat 4 and 5), images almost completely free of clouds were much less abundant. Therefore, the dates of the images acquired were not regularly spread through time, suggesting that methodologies such as the change vector analysis did not seem suitable.

Finally, the subtraction of images was chosen for its simplicity and because of its robustness; moreover, this method has been frequently used in studies with similar objectives (Kasischke et al. 1993, Kasischke and French 1995, Fernández et al. 1997, Cohen et al. 1998), but using shorter series and in some cases without radiometric correction of the images. Specifically, a sudden decrease in NDVI values between images before and after the fire was expected. Less predictable, however, could be the evolution of NDVI values of fire scars in the series of images following the fire ( Salvador and Pons 1996). In this previous study, the evolution of NDVI after the fire was highly variable, sometimes increasing quickly, or slowly, or even remaining stable. Therefore, the significant decrease in NDVI values between pre-fire and post-fire images appeared as the clearest sign to detect burned areas.

\subsection{Use of masks}

As it might be expected, there were other types of surfaces that yield a sudden drop in NDVI values between subsequent images. Among them, crops, clouds, freshwaters and deciduous forests, were present in our study area. To avoid confusions between these surfaces and burned areas a set of masks was created and applied to the series of images.

Hence, a mask with all crops was obtained from the Corine-Land Cover Map. Deciduous forests, which were not usually aFected by fires, were discriminated by means of a pair of winter-summer images in which their phenology was specially conspicuous. Clouds appeared as dark spots in the NDVI images and had high reflectance values in the original bands, which were used to create masks for every NDVI image (specifically, band $2(0.6-0.7 \mathrm{~mm})$ was used). However, masks failed to detect cloud edges since their reflectance values were much lower than those found in cloud cores. Cloud edges were finally included in masks by spatially expanding the pixels of original cloud masks. A further problem appeared in images with large areas covered with clouds since, although clouds could be successfully detected by masks, the probability of rejecting one area with a hidden fire scar (under the clouds) 
was considerable. This problem was minimised through the division of full frames in sub-windows (see below in §3.6). Finally, freshwaters where also easily controlled by means of a reclassification of the Corine-Land Cover map.

A number of factors were relevant when considering the minimum area to be taken into account in this study. Besides the minimum sizes given by the pixel resolution and by co-registration problems, slightly bigger sizes may still lead to the appearance of an unmanageable number of small patches coming from local events such as new buildings, agriculture management, new roads and infrastructure s (see Kasischke et al. 1993). After some visual trials we set the minimum area of change at $30 \mathrm{ha}$.

\subsection{Detection thresholds}

Threshold determination may be carried out in three diFerent ways. Firstly, values may be fixed on a theoretical basis. This option requires a high level of reliability in radiometric corrections, and suficient correspondence between theoretical conditions and those truly found in the image. Such conditions were not satisfied in our study due to some radiometric processing problems existing in such a long time series.

The second possibility was to use a statistical approach, considering pixels located more than a particular number of standard deviations (usually 2Ös) from the mean value of the subtraction image (expected near 0) (Fung and Le Drew 1988, Fernández et al. 1997). This method is based on the probability of extracting from a normal population, an individual outside the interval given by môYÖs (where $m$ is the population mean and $Y$ is a value, usually 1, 2 or 3). However, a complete satellite image cannot be considered as a sample but rather as a complete census, where every individual (pixel), including those more extreme, is measured. Thus, a systematic error would be committed using this method because we would always reject $5 \%$ (or the equivalent proportion to YÖs) of the most extreme values in the population, considering them to come from another population (the one of burned pixels).

Finally, the last considered approach was empirical, visually seeking the threshold value that yielded best results (Kasischke et al. 1993). This was the selected one, but using a methodology that gave a threshold value for every pair of images (see below).

Preliminary trials showed that the optimal threshold shifted considerably among the subtraction images. This might be expected, considering the following factors:

1. The type of vegetation burned influences NDVI response giving greater NDVI diFerences for a fire in a forested area than those produced in a shrub-covered area.

2. Images from diFerent seasons produce diFerent responses. For example, subtraction of two summer images may produce quite a diFerent response compared to the one of a subtraction of a spring and a summer image. In the latter case, the summer image will have low NDVI values due to moisture stress aFecting the Mediterranean vegetation. This stress is more evident in shrubby zones (where the herbaceous understorey dries out) than in densely forested zones where canopies respond steadily (Gamon et al. 1995).

3. Images from diFerent sensors (Landsat MSS 1, 2, 3 and 5) may have diFerent radiometric responses due to problems in the radiometric correction process.

4. The radiometric correction model employed assumes a horizontally homogen- 
clouds and other variable surfaces) (ESA 1979a, 1979b). Eventually we opted to including important height fluctuations, such as the one studied here.

To minimise the eFect of some of the above-mentione $d$ factors and to provide a NDVI threshold for every possible situation the total study area was divided into 31 sub-windows, for which we could assume a similar type of vegetation and environmental conditions.

The empirical choice of thresholds was based on a visual interpretatio $n$ of the images. Specifically, a total amount of 21 previously known fires located in diFerent sub-windows were used to analyse the magnitude of decreases in NDVI values. Thus, for each one of these burned areas, a range of values concerning NDVI decreases was obtained, so that within each range the fire scar analysed could be clearly discriminated. These ranges of possible threshold values (in fact containing potential thresholds to be used in the discrimination process) were given in relation to the diFerence in mean NDVI values between the pair of sub-window images which included each fire (both in a temporal and in a spatial sense) (see figure 2). Here it is important to notice that such mean NDVI values were calculated from the totality of pixels in the subimage (not only from the burned ones). Next, two diFerent methods, based on simple linear regressions, were applied to obtain the models that were finally used to assign specific values of thresholds to every pair of sub-window images along the whole time series (see figures 3 and 4). (The division in 31 subwindows is useful to apply the two methods in a particular way for each geographic area; moreover, these subwindows conveniently overlap to guarantee that any significant fire scar is always covered by at least one subwindow.)

Method of the iterated threshold (method 1): Using the centres of threshold intervals of all 21 fire scars as initial points to be adjusted in a simple regression, an iterative fitting process was performed towards convergence to a lineal model which was the closest to all the intervals. Specifically, expected values from one fitting were used as observed values for the next iteration in case they were still found within its

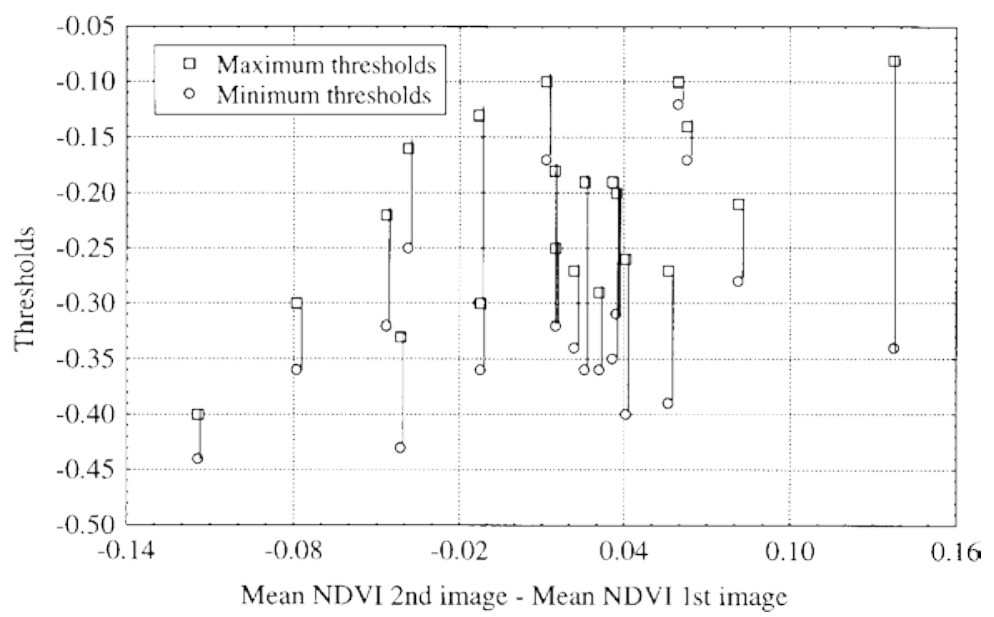

Figure 2. Intervals of NDVI values, given by a maximum and a minimum threshold, within which the 21 fires analysed were correctly observed. These intervals are given as a function of the diFerences between the mean NDVI values of the subimages previous and following to the fire events. 


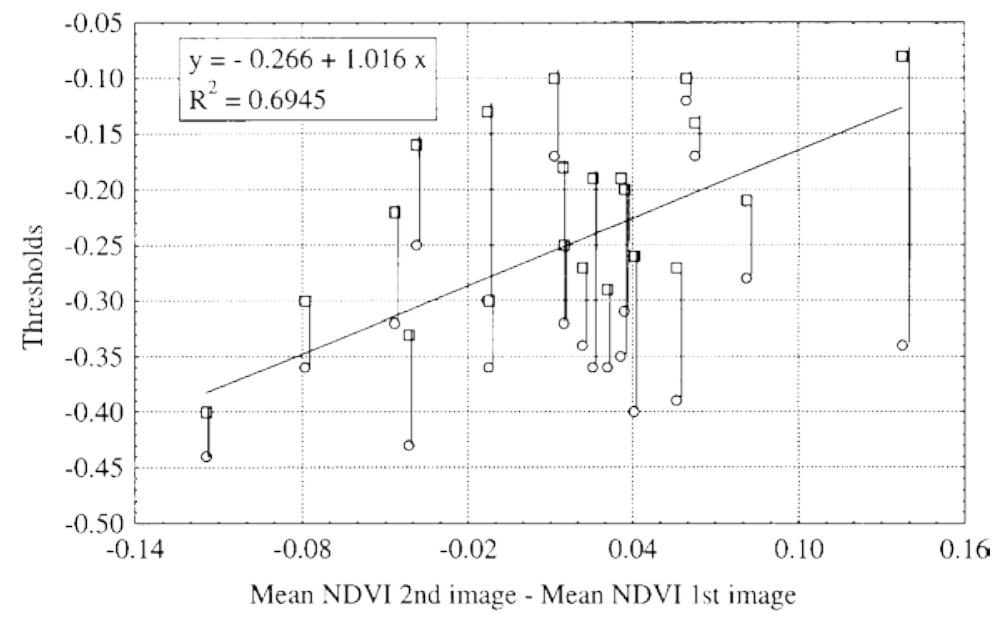

Figure 3. Method 1 (iterated threshold) for threshold selection. The lineal model fits the NDVI intervals shown in figure 2.

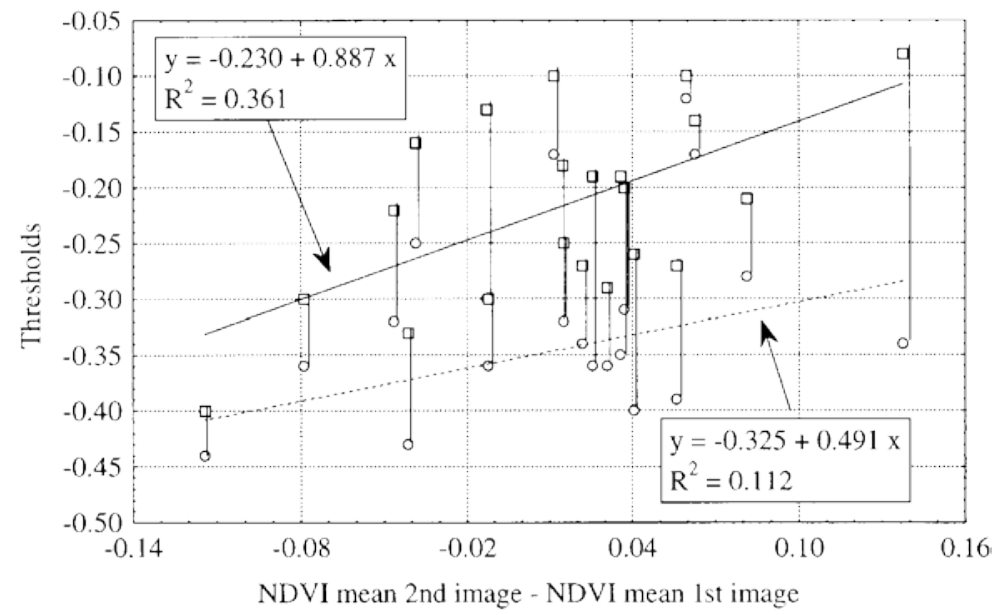

Figure 4. Method 2 (double threshold) for threshold selection. The lineal models fit the maximum and minimum NDVI values shown in figure 2.

correspondent interval; otherwise the extreme value of the interval was given as observed value (see figure 3 ).

Method of the seed or double threshold (method 2): This method performs two simple linear fittings, one on the maximum values and another one on the minimum values of the threshold intervals (see figure 4). The former is used to give less restrictive thresholds and allows obtaining a best mapping of shapes and perimeters of the burned area. However, it also considers as burned many other areas that only respond to high phenological variations. On a second step, to avoid these undesirable patches, areas burned are detected according to the model fitted to the minimum values of intervals (the most restrictive). The resultant fire scars do not often seem to correctly preserve shapes and perimeters of fires because of the restrictive threshold applied. However, they can be used as seeds on the model fitted using the maximum 
values to discriminate burned from non-burned areas. Specifically, only the areas and perimeters detected by the less restrictive thresholds that kept some pixels when the more restrictive thresholds were applied, were considered as valid fire scars (see figure 5).

In short, the aim of the two methods, 1 and 2, is to use the best threshold over the subtraction images, detecting as many fires as possible but avoiding to misinterpret decreases of NDVI due to other land cover changes as fires. Figure 5 illustrates an example on how both methods work.

\section{Results}

Both methods were applied to each consecutive pair of sub-images derived from the 31 sub-windows, producing a set of areas characterised by a considerable drop in NDVI values. Figures 6 and 7 show, in a single map, all the patches detected by both methods during the period 1975-1993. Both maps are the synthesis of several dozens of maps of the area over the time and space (satellite frames).

A visual analysis of both maps highlights the most important diFerences between the results of both methods. Method 1 (iterated threshold) seems to map a significantly higher number of patches with a small size. By contrast, method 2 (double threshold) appears to maintain the continuity of large patches. Table 1 shows the number of pixels detected as burned by each method according to the recurrence level of burning. However, although informative, this visual analysis, does not give an objective assessment of the success of the fire detection. Consequently it was necessary to access to independent information to quantify the mapping accuracy. The local Government provided field information about the location of fires that occurred during the period 1983-1993 at the municipality level (i.e. the territory under municipal jurisdiction). Hence, it was possible to check if each fire scar detected from the images in a given period of time had been registered by the municipality, and conversely, if every fire registered by each municipality was detected from the remotely sensed images.

Figure 8 gives the percentage of the total number of fire scars (patches) detected by both methods in relation to the wildfires inventoried by the local government corresponding to the estimation of omission error. Method 1 discriminated $53.36 \%$ of fires greater or equal than 30 ha (175 fires), notably more than the $43.60 \%$ of fires detected by method 2 ( 143 fires). Visual analysis of figures 6 and 7 suggests that the higher error of omission for method 2 is due to the considerably lower number of small patches discriminated. On the other hand, as it was expected for both methods, the degree of detection improved as the size of fires increased, reaching $78 \%$ for fires of 200 ha. Nevertheless, the absolute number of fires decreased significantly as the minimum area increased (see figure 10).

In addition to the error arising from real fires not being detected, the accuracy should also be quantified in terms of the error arising from mapped areas which do not really belong to burned patches (i.e. commission error). Figure 9 shows, for both methods, the proportions of discriminated areas that did not correspond to real fires. In this case, unlike the omission error, considering all the fires greater or equal than 30 ha, the accuracy of method $2(91.08 \%)$ was quite superior to that of method 1 (75.73\%) since gives a lower number of patches (see figures 6 and 7 ). Mapping accuracy increased with the minimum area considered, as it did for the omission error, but in this case success levels were generally significantly greater. Most of 


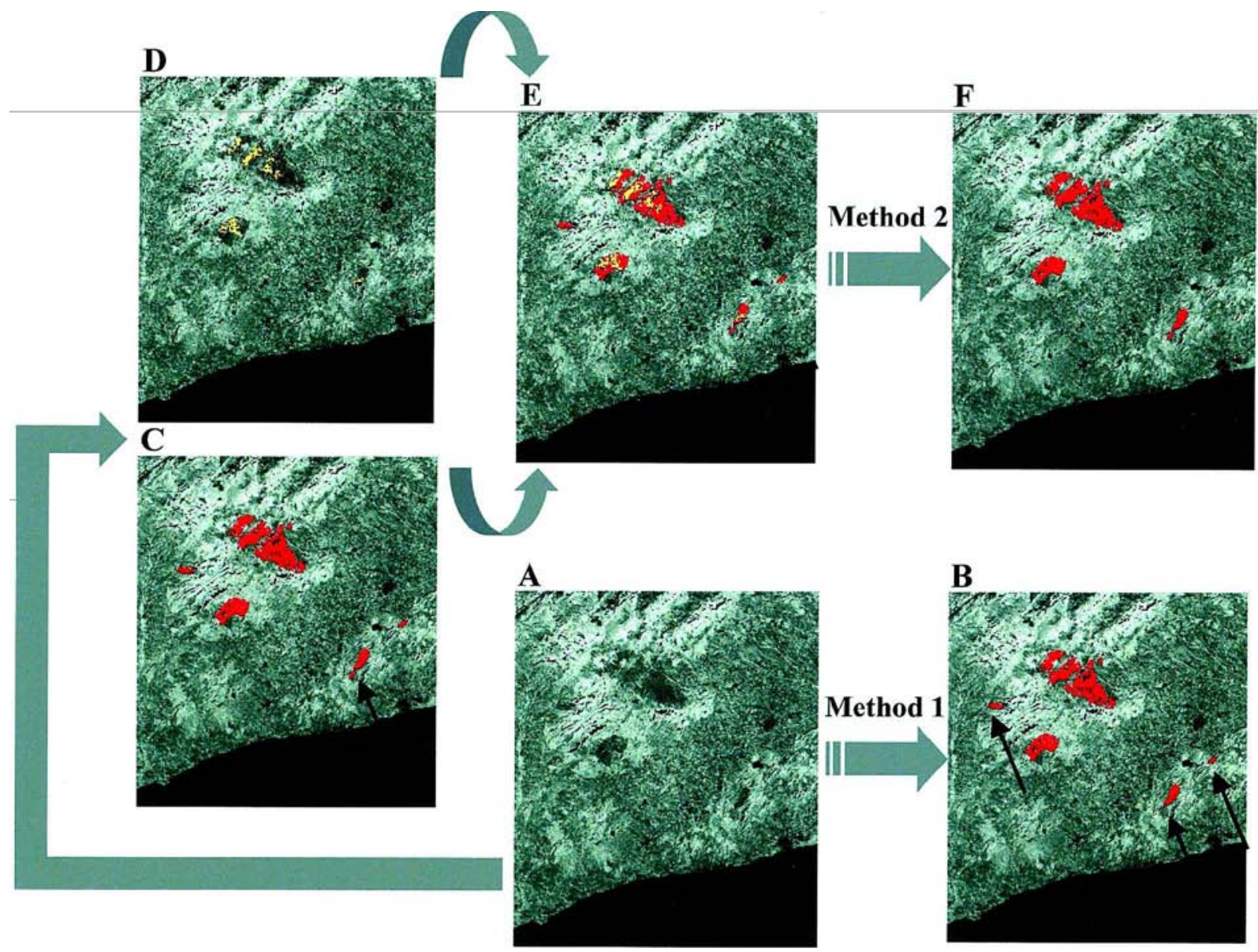

Figure 5. The two methods proposed to discriminate the fire scars. Image A represents the NDVI values of a region in 1986, after several wildfires. The subtraction values between such image and the previous one (1985) are used to apply diFerent thresholds. Image B shows the result using the method 1 (see figure 3). Images $C$ to $F$ shows the result using the method 2 (see figure 4): image $C$ highlights the burned zones detected when applying the maximum thresholds, and image D shows the burned zones for the minimum thresholds; image $E$ overlays $C$ and $D$, and is used to obtain the definitive outcome (F) of method 2 (see text for details). The considerable diFerences are marked by an arrow. 


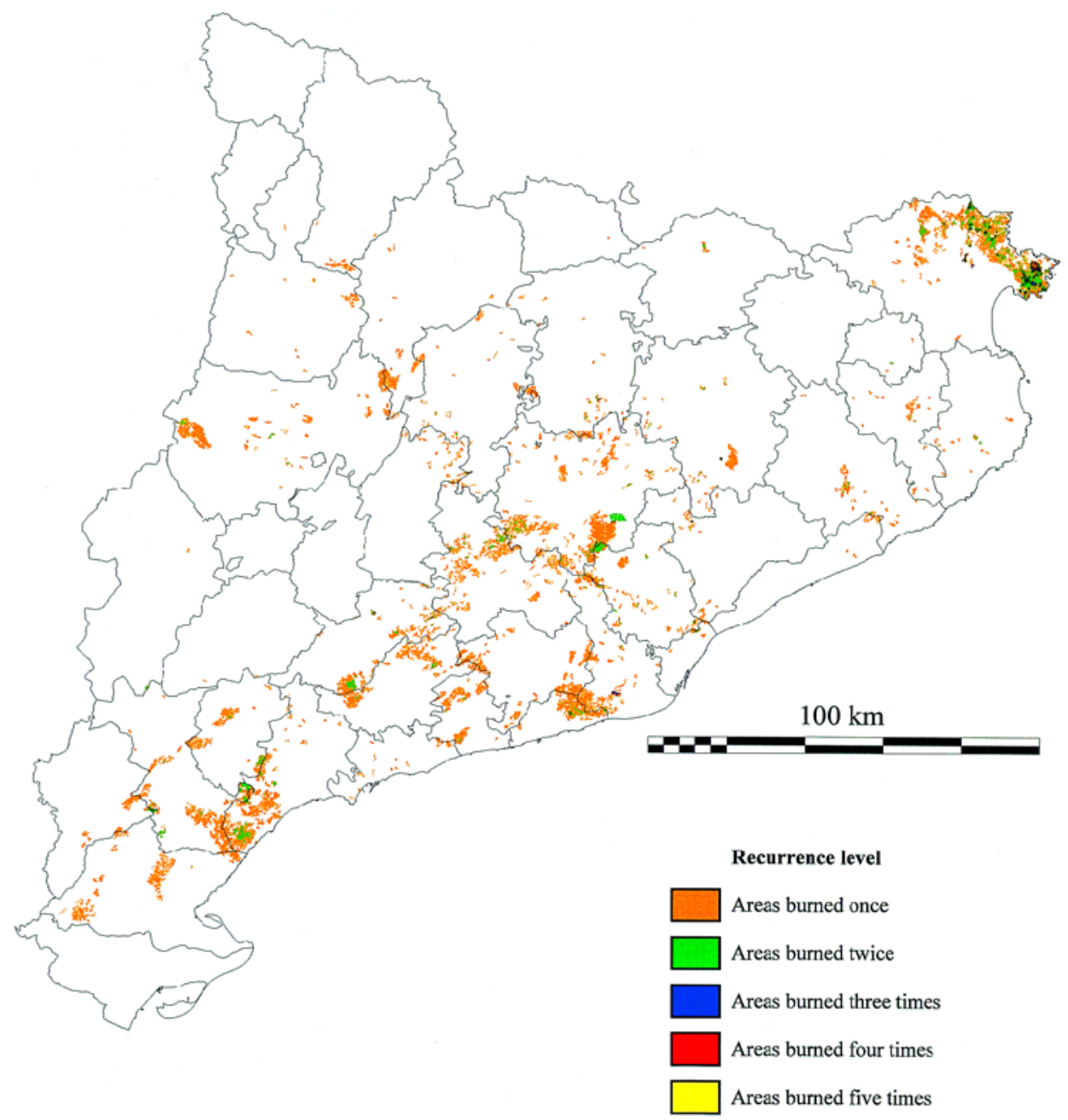

Figure 6. Map of areas burned and frequency of wildfires in Catalonia during the period 1975-93. Method 1.

'fictitious' patches, often of small size, obtained with method 1, corresponded to sparse shrub communities. This kind of land cover shows a strong phenological variability due to the herbaceous understorey that dries out during summer time. This behaviour can produce some reductions in NDVI values similar to that caused by fires within this kind of vegetation community. Indeed, because of the low cover percentage the NDVI reduction upon burned areas is not sharp. It is also important to note that some 'ficticious' fire scars correspond, in some cases, to gaps in the fire statistics, so that the commission error figures are expected to be somewhat lower.

In summary, mapping fire scars with a minimum area of 30 ha produced lower commission errors than omission errors. For both methods, the degree of success 


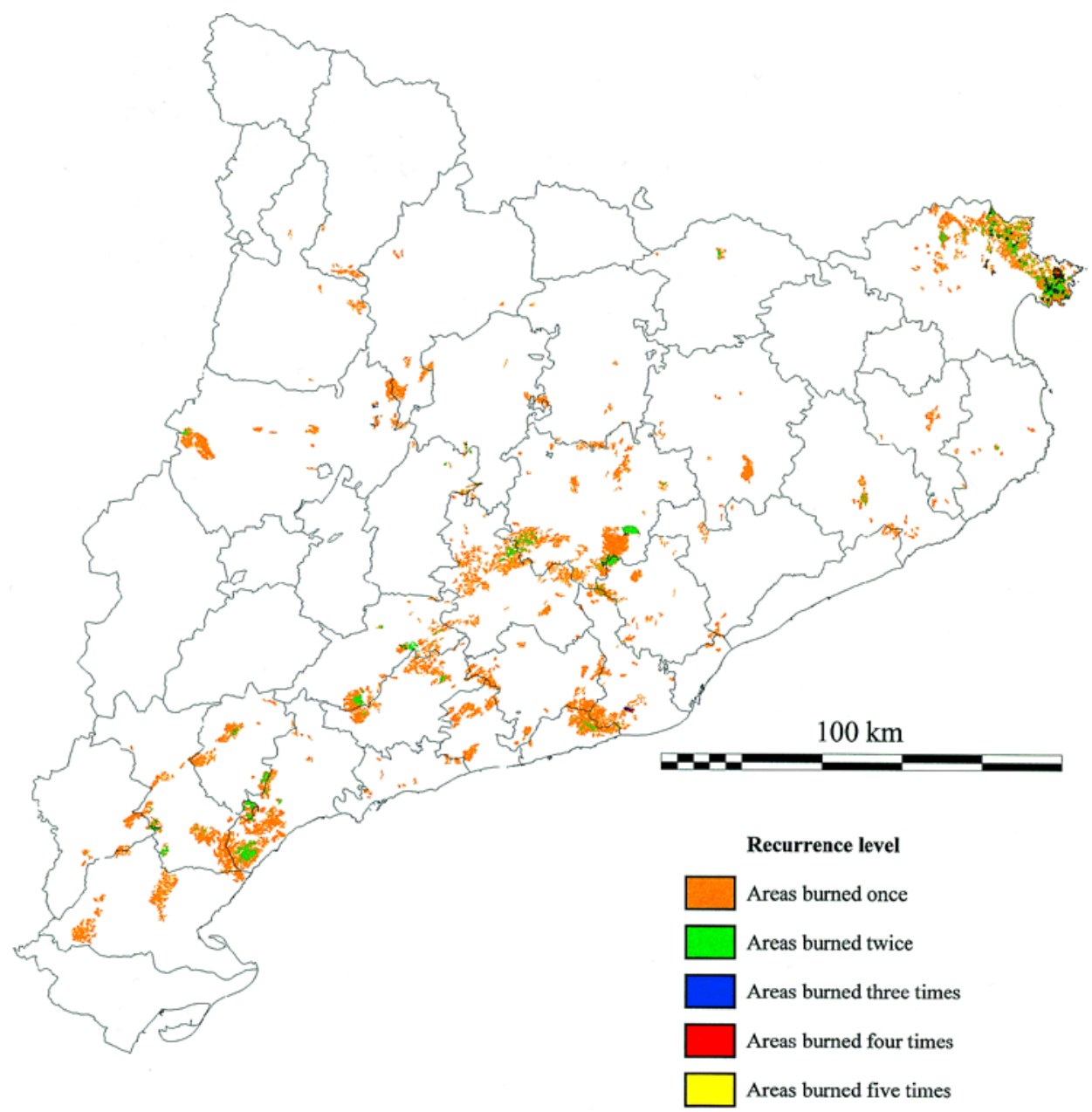

Figure 7. Map of areas burned and frequency of wildfires in Catalonia during the period 1975-93. Method 2.

Table 1. Number of pixels $(60 \mathrm{mÖ} 60 \mathrm{~m})$ detected as burned by each method according to the recurrence level of burning. Figures in parenthesis give the percentage of the burned area.

\begin{tabular}{lcc}
\hline Recurrence level & Double threshold & Iterated threshold \\
\hline Once burned & $472344(7.50)$ & $470243(7.48)$ \\
Twice burned & $69542(1.10)$ & $65519(1.04)$ \\
Three times burned & $6746(0.107)$ & $6285(0.100)$ \\
Four times burned & $1291(0.020)$ & $1096(0.017)$ \\
Five times burned & $186(0.0029)$ & $203(0.0032)$ \\
Total burned & $550109(8.75)$ & $543346(8.64)$ \\
\hline
\end{tabular}

clearly improved when increasing the minimum area considered as burned. Finally, when comparing the two methodologies of detection, method 2 yielded lower omission errors while method 1 produced lower commission errors. 


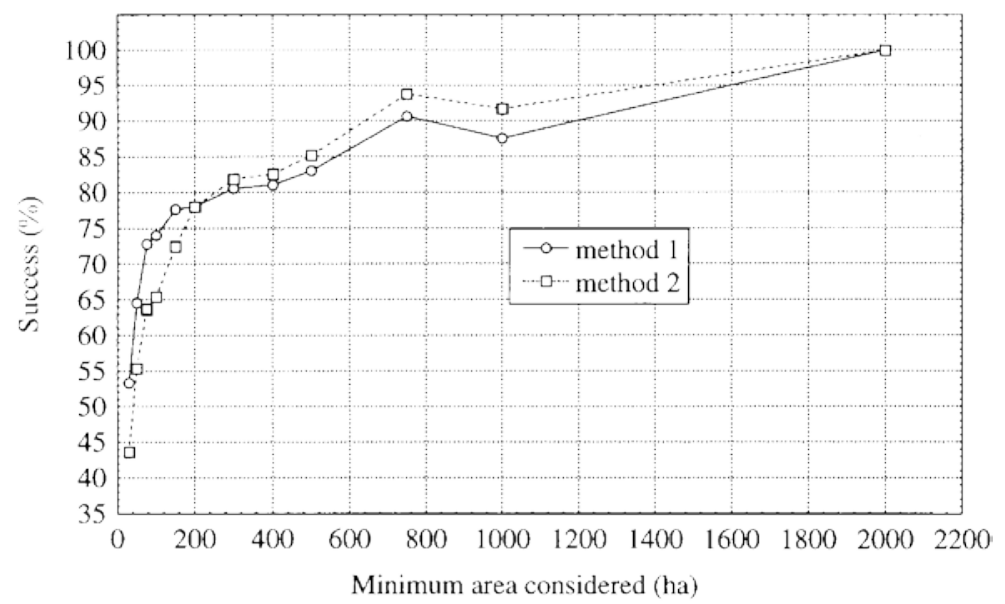

Figure 8. Percentage of success given as: (number of real fires detected/total number of real fires) Ö 100 versus minimum area considered. This value is complementary to the omission error.

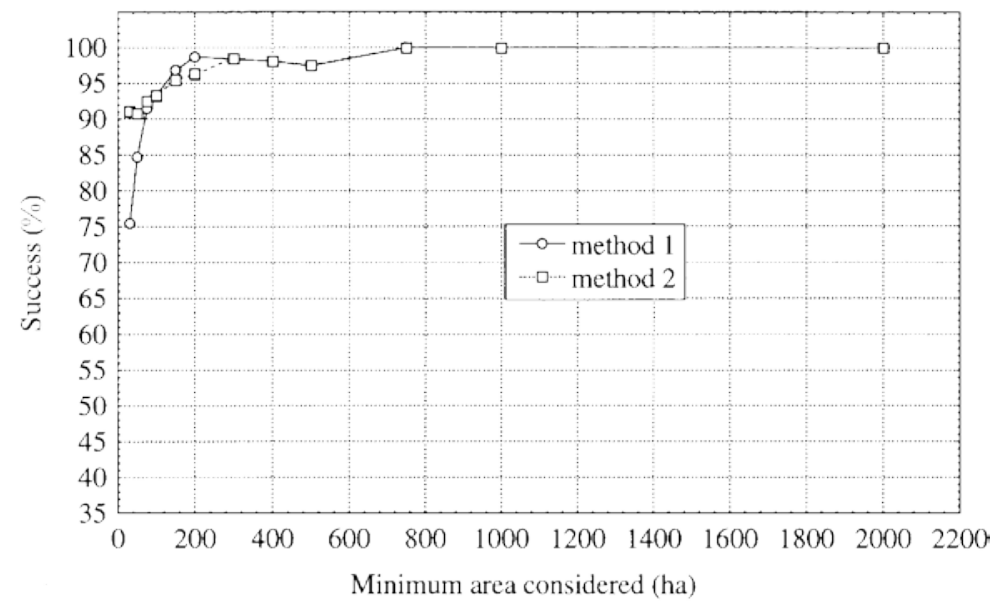

Figure 9. Percentage of success given as: (number of real fires detected/total number of fires detected) Ö 100 versus minimum area considered. This value is complementary to the commission error.

\section{Discussion}

Figures 3 and 4 suggest that using a linear model to obtain specific thresholds will not always yield the best estimates, even though it produces considerably better results than using a single threshold value. However, most of the variation in the fittings does not seem to follow a coherent pattern in relation to the independent variable, possibly suggesting that such variation has a residual origin which can be attributed to diFerent causes.

First, it was not possible to acquire images recorded on the same period each year as it would be suitable to get rid of the intraanual phenologic noise (Lambin, 1996). Nevertheless, the models fitted are supposed to have minimised the eFects of such phenological fluctuations. 


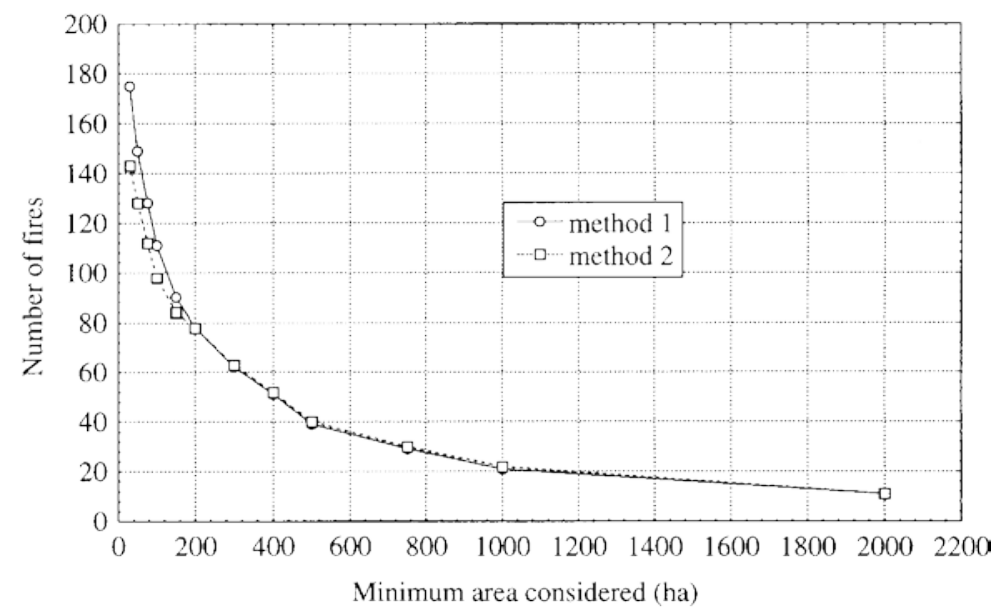

Figure 10. Absolute number of fires detected by both methods versus the minimum area considered. Fires equal or bigger than the minimum size given are considered in each interval.

Another more serious consequence of the lack of images arose when there was a long time period between the fire and the first recorded image. In these situations the drop in NDVI values could be concealed by the appearance of 'new' vegetation in the burned area as a consequence of rains and plant resprouting (it should be noted that NDVI response becomes rapidly saturated when plant recovery is complete). Thus, if regeneration is eFective, the fire may be undetectable. This phenomenon has been observed in other studies such as those by Kasischke et al. (1993), Masselli et al. (1996) and Pereira and Setzer (1996). This phenomenon will be more troublesome in areas with sparse vegetation, where initially low percentage of cover will be easily re-established.

There are several factors that make detection of fires in sparse vegetation dificult. First of all, these areas are more phenologically dynamic than perennial forests. Inclusion of the radiometric response from soils and lithology can also lead to a variation in the NDVI not attributabl e to vegetation. In addition, because of their lower percentage of cover, sparse shrub areas show a smaller reduction of the NDVI values after fire. It should be emphasised that the models in figures 3 and 4 do not directly consider the degree of vegetation coverage that has undergone the fire; such consideration could lead to future improvements of the presented methodology.

Although images from the same sensor for the multitempora I series from 1975 to 1993 have been employed, substantial changes in the quality of the images could be expected throughou t this period. Drift in the sensor response can be expected as time goes by after the satellite launch. These changes are not expected to have significantly aFected the results because of the final normalisatio $\mathrm{n}$ process applied over the complete set of images (see §3.3).

On the other hand, some inaccuracies in the radiometric correction process, mainly due to horizontal atmospheric heterogeneity, could be minimised by the use of sub-windows (see §3.5) during the threshold selection process.

There may be other factors that could lead to some problems when detecting fire scars with this method. One is the practice, traditional in this region, of forest cutting. Another one is the variability in the intensity of fire, which is influenced by factors such as meteorological conditions, relief, specific composition of vegetation, 
etc. For example there are wildfires that only aFect the understorey, and which may not be detected as easy as crown fires. Finally, the validity of tests carried out on the results of this study should be considered taking into account that governmental surveys used as ground truth have their own inaccuracies (either in fires counting or fire extent), making dificult the precise assessment of the error.

\section{Conclusions.}

Satellite images have a considerable value for mapping burned areas. Despite technical problems due to its age, images from the MSS sensor are particularly useful for the task of fire mapping. Knowledge about these areas can aid to understand the recovery dynamics of the vegetation communities after fire as shown by DlazDelgado et al. (1998). On the other hand, there is a global and regional interest in monitoring and describing fire regimes. Such monitoring gives a valuable amount of information in order to evaluate the most aFected zones by fire and the possible implied causes, or even may assist the analysis of carbon fluxes between biosphere and atmosphere.

The linear models developed in this analysis, although based on a simple method such as NDVI subtraction, have produced quite acceptable results. When comparing both methods developed, method 1 initially gave lower omission errors, while method 2 yielded the best results in relation to commission errors. Nevertheless, both methods are quite conservative, giving clearly lower commission errors than omission errors.

\section{Acknowledgments}

We would like to thank the Institut Cartogrà fic de Catalunya for the help supplied in the geometrical correction of the images and the Departament d'Agricultura, Ramaderia i Pesca (DARP, Generalitat de Catalunya) and the Instituto para la Conservación de la Naturaleza (ICONA) for the statistical data supplied. Also, we acknowledge the special aid of Dr Megan Lewis (University of Adelaide, South Australia) for reviewing the preliminary paper. This project was funded by a grant provided by the Comisión Interdepartamental de Ciencia y Tecnologla (CICYT AMB94-0881), by the LUCIFER EC project (ENV-CT96-0320), by a fellowship from the Generalitat de Catalunya to Raimon Salvador and by a fellowship from the Ministerio de Educación y Cultura to Ricardo Dlaz-Delgado.

\section{References}

Anderson, G. L., Hanson, J. D., and Haas, R. H., 1993, Evaluating Landsat Thematic Mapper derived vegetation indices for estimating above-ground biomass on semiarid rangelands. Remote Sensing of Environment, 45, 165-175.

Bannari, A., Huete, A. R., Morin, D., and Zagolski, F., 1996, EFets de la coleur et de la brillance du sol sur les indices de végétation. International Journal of Remote Sensing, 17, 1885-1906.

Blackburn, G. A., and Milton, E. J., 1995, Seasonal variations in the spectral reflectance of deciduous tree canopies. International Journal of Remote Sensing, 16, 709-720.

Callaway, R. M., and Davis, F. W., 1993, Vegetation dynamics, fire, and the physical environment in coastal central California. Ecology, 74, 1567-1578.

Chavez, P. S., and Kwarteng, A. Y., 1989, Extracting spectral contrast in Landsat Thematic Mapper image using selective principal component analysis. Photogrammetric Engineering and Remote Sensing, 55, 339-348.

Chuvieco, E., and Martin, M. P., 1994, Global fire mapping and fire danger estimation using AVHRR images. Photogrammetric Engineering and Remote Sensing, 60, 563-570.

Chuvieco E., 1996, Fundamentos de Teledetección Espacial, third edition (Madrid: Rialp).

Cohen, W. B., Fiorella, M., Gray, J., Helmer, E., and Anderson, K., 1998, An eficient and accurate method for mapping forest clearcuts in the Pacific Northwest using Landsat imagery. Photogrammetric Engineering and Remote Sensing, 64, 293-300. 
Collins, J. B., and Woodcock, C. E., 1996, An assessment of several linear change detection techniques for mapping forest mortality using multitemporal Landsat TM data. Remote Sensing of Environment, 56, 66-77.

Danson, F. M., and Plummer, S. E., 1995, Red-edge response to forest leaf area index. International Journal of Remote Sensing, 16, 183-188.

Davis, F. W., and Burrows, A., 1994, Spatial simulation of fire regime in Mediterraneanclimate landscapes. In The Role of Fire in Mediterranean-Type Ecosystems, edited by J. M. Moreno and W. C. Oechel (New York: Springer-Verlag), pp. 117-139.

Diaz-Delgado, R., Salvador, R., and Pons, X, 1998, Monitoring of plant regeneration after fire by remote sensing. In Fire Management and Landscape Ecology, edited by Louis Trabaud (Fairfield, Washington, International Association of Wildland Fire), pp. 315-326.

Di Maio, A. C., and Setzer, A. W., 1997, Deforestation detection in the Amazon with an AVHRR-based system. International Journal of Remote Sensing, 18, 273-286.

Duncan, J., Stow, D., Fanklin, J., and Hope, J., 1993, Assessing the relationship between spectral vegetation indices and shrub cover in the Jornada Basin, New Mexico. International Journal of Remote Sensing, 14, 3395-3416.

Eastman, J.R., and FuIk, M., 1993, Long sequence time series evaluation using standardised principal components Photogrammetric Engineering and Remote Sensing, 6, 991-996 (EOSAT, 1986, Landsat Technical Notes, USA).

ESA, 1979a, Format specifications for Landsat MSS system corrected computer compatible tapes. EPO/80-685/SB/gg, Italy.

ESA, 1979b, Format specifications for Landsat MSS system corrected computer compatible tapes. EPO/80-545/SB/gg, Sweden.

Fernández, A., Illera, P., and Casanova, J. M., 1997, Automatic mapping of surfaces aFected by forest fires in Spain using AVHRR NDVI composite image data. Remote Sensing of Environment, 60, 153-162.

Folch, R., 1986, La vegetació dels Pał̀sos Catalans, second edition (Barcelona: Ketres Editora S.A.).

Foody, G. M., Palubinskas, G., Lucas, R. M., Curran, P. J., and Honzak, M., 1996, Identifying terrestrial carbon sinks: classification of successional stages in regenerating tropical forest from Landsat TM data. Remote Sensing of Environment, 55, 205-216.

Fung, T., and Le Drew, E., 1987, Application of principal components analysis to change detection. Photogrammetric Engineering and Remote Sensing, 12, 1649-1658.

Gamon, J. A., Field, C. B., Goulden, M. L., Griffin, K. L., Hartley, A. E., Joel, G., Penuelas, J., and Valentini, R., 1995, Relationships between NDVI, canopy structure, and photosynthesis in three Californian vegetation types. Ecological Applications, 5, 28-41.

Gracia, C., and Sabaté, S., 1996, La resposta de la vegetació al foc: els canvis en l'estructura de la vegetació. In Ecologia del Foc, edited by J. Terradas (Barcelona: Proa), pp. 162-172.

Gracia, C., Ibanez, J. J., Vayreda, J. Pons, X., and Terradas, J., 1997, Un nuevo concepto de inventario forestal. In Proceedings of the XI world forestry congress (Antalya, Turkey: World Forestry Association), p. 43.

Hall, F. G., Botkin, D. B., Strebel, D. E., Woods, K. D., and Goetz, S. J., 1991, Large-scale patterns of forest succession as determined by remote sensing. Ecology, 72, 628-640.

Huete, A. R., 1988, A soil-adjusted vegetation index (SAVI). Remote Sensing of Environment, 25, 295-309.

Johnston, E. A., and GutselI, S. L., 1994, Fire frequency models, methods and interpretations. Advances in Ecological Research, 25, 239-283.

Kasischke, E. S., French, H. F., HarrelI, P., Christiensen, N. L., Ustin, S. L., and Barry, D., 1993, Monitoring of wildfires in boreal forests using large area AVHRR NDVI composite image data. Remote Sensing of Environment, 45, 61-71.

Kasischke, E. S., and French, H. F., 1995, Locating and estimating the areal extent of wildfires in Alaskan boreal forests using multiple-season AVHRR NDVI composite data. Remote Sensing of Environment, 51, 263-275.

Lambin, E. F., 1996, Change detection at multiple temporal scales: seasonal and annual variations in landscape variables. Photogrammetri c Engineering and Remote Sensing, 62, 931-938.

Lambin, E. F., and Strahler, A. H., 1994a, Change-vector analysis in multitemporal space: a tool to detect and categorize land-cover change processes using high temporal-resolution satellite data. Remote Sensing of Environment, 48, 231-244. 
Lambin, E. F., and Strahler, A. H., 1994b, Indicators of land-cover change for change-vector analysis in multitemporal space at coarse spatial scales. International Journal of Remote Sensing, 15, 2099-2119.

Ludovic, A., Salas, W. A., and Skole, D., 1994, Fourier analysis of multitemporal AVHRR data applied to land cover classification. International Journal of Remote Sensing, 15, $1115-1121$.

MasseIIi, F., Conese, C., Rodolfi, A., and Bottai, L., 1996, Characterisation of forest recovery after fires in a Mediterranean area by means of multitemporal Landsat TM scenes. In Progress in Environmental Remote Sensing Research and Applications, edited by Parlow ( Balkema: Rotterdam), pp. 73-76.

Mather, P.M., 1987, Computer processing of remotely-sensed images (New York: John Wiley \& Sons).

Minnich, R. A., 1983, Fire mosaics in Southern California and Northem Baja California. Science, 219, 1287-1294.

Moreno, J. M., Vazquez, A., and Velez, R., 1998, Recent history of forest fires in Spain. In L arge forest fires, edited by J. M. Moreno (Leiden, The Netherlands: Backhuys Publishers), pp. 159-185.

Nieuwenhuis, A., 1987, The eFect of fire frequency on the sclerophill vegetation of the West Head, New South Wales. Australian Journal of Ecology, 12, 373-385.

Palà, V., and Pons, X., 1995, Incorporation of relief into geometric correction based on polynomials. Photogrammetr ic Engineering and Remote Sensing, 7, 935-944.

Pereira, M. C., and Setzer, A. W., 1993, Spectral characteristics of fire scars in Landsat-5 TM images of Amazonia. International Journal of Remote Sensing, 14, 2061-2078.

Pereira, M. C., and Setzer, A. W., 1996, Comparison of fire detection in savannas using AVHRR's channel 3 and TM images. International Journal of Remote Sensing, 17, 1925-1937.

Pinol, J., Terradas, J., and LIoret, F., 1998, Climate warming, wildfire hazard, and wildfire occurrence in coastal eastern Spain. Climatic change, 38, 345-357.

Pons, X., and Solé-Sugranes, L., 1994, A simple radiometric correction model to improve automatic mapping of vegetation from multispectral satellite data. Remote Sensing of Environment 48, 191-204.

Qi, J., Huete, A. R., Moran, M. S., Chehbouni, A., and Jackson, R. D., 1993, Interpretation of vegetation indices derived from multitemporal Spot images. Remote Sensing of Environment 44, 89-101.

Qi, J., Chehbouni, A., Huete, A. R., Kerr, Y. H., and Sorooshian, S., 1994, A modified soil adjusted vegetation index. Remote Sensing of Environment, 47, 1-25.

Razafimpanilo, H., Frouin, R., lacobellis, S. F., and Somerville, C. J., 1995, Methodology for estimating burned area from AVHRR reflectance data. Remote Sensing of Environment, 54, 273-289.

Richards, J. A., 1984, Thematic mapping from multitemporal image data using the principal components transformation. Remote Sensing of Environment, 16, 35-46.

Sader, S. A., 1995, Spatial characteristics of forest clearing and vegetation regrowth as detected by Landsat Thematic Mapper imagery. Photogrammetr ic Engineering and Remote Sensing, 61, 1145-1151.

Salvador, R., and Pons, X., 1996, Analysis of the discrimination of burnt sites temporal evolution in a Mediterranean area. EARSeL Advances in Remote Sensing, 4, 159-169.

Steininger, M. K., 1996, Tropical secondary forest regrowth in the Amazon: age, area and change estimation with Thematic Mapper data. International Journal of Remote Sensing, 17, 9-27.

Terradas, J., and Pinol, J., 1996, Els grans incendis: condicions meteorològiques i de vegetació per al seu desenvolupament. In Ecologia del Foc, edited by J. Terradas (Barcelona: Proa), pp. 63-75.

Vélez, R., 1996, Les feux de forêt dans le sud de I'Union Europeenne 1989-1993. (Luxembourg: Commission Europeenne).

Veroustraete, F., Patyn, J., and Myneni, R. B., 1996, Estimating net ecosystem exchange of carbon using the normalised diFerence vegetation index and an ecosystem model. Remote Sensing of Environment, 58, 115-130.

Xia, L., 1994, A two-axis adjusted vegetation index (TWVI). International Journal of Remote Sensing, 15, 1447-1458. 